\title{
Peripheral Facial Palsy and Communicating Hydrocephalus as a Clinical Presentation of Hemorrhagic Vestibular Schwannoma: Case Report
}

\section{Paralisia facial periférica e hidrocefalia comunicante como apresentação Schwannoma vestibular hemorrágico: relato de caso}

\author{
João Monteiro Silva ${ }^{1}$ Mário Gomes ${ }^{1}$ Ernesto de Carvalho ${ }^{1}$ \\ ${ }^{1}$ Department of Neurosurgery, Centro Hospitalar do Porto, \\ Porto, Portugal \\ Arq Bras Neurocir 2018;37:63-66. \\ Address for correspondence João Daniel Monteiro Silva, MD, Serviço \\ de Neurocirurgia do Centro Hospitalar do Porto, Largo Professor Abel \\ Salazar 4099-001 Porto, Portugal \\ (e-mail: jdanielmonteiro@gmail.com).
}

\begin{abstract}
The vestibular schwannoma is the most common extra-axial tumor of the posterior fossa. Hemorrhage associated with vestibular schwannomas has been described in less than $1 \%$ of the cases. The etiology remains unknown; however, some risk factors have been suggested, such as tumor size and tumor growth rate, the vascularity and histopathology of the tumor or even previous treatment with radiosurgery. The present case is of a 74-year-old female patient, who presented to our clinic in December of 2015 after a mild traumatic brain injury. In that context, she did a brain computed tomography (CT) scan and was diagnosed with a vestibular schwannoma- an incidentaloma. It was decided at that time to treat the patient

Keywords

- vestibular schwannoma

- brain hemorrhage

- hydrocephalus

- peripheral facial paralysis conservatively because of her comorbidities and the presentation of the disease. In March of 2017, the patient presented again to our clinic with a right peripheral facial paralysis (House-Brackmann [HB] grade IV-VI) and confusion. The CT scan revealed that bleeding around the vestibular schwannoma had caused the clinical presentation. We decided to treat the hydrocephalus with a ventriculoperitoneal shunt. At the time of her last follow-up visit, the confusion symptoms had resolved, and her right-sided facial function had improved to a HB grade II-VI.
\end{abstract}

\section{Introduction}

Vestibular schwannomas (VSs) are the most common extraaxial tumors of the posterior fossa-they account for $\sim 75 \%$ of all cerebellopontine angle (CPA) tumors. ${ }^{1,2}$ The most common presentation of a VS is cochlear nerve impairment (95\% of cases), followed by others like gait ataxia, vertigo, vestibular nerve impairment or, even less common presentations such as facial nerve or trigeminal nerve impairment. Historically, hemorrhage associated with VS had been described in less

received

October 30, 2017

accepted

December 18, 2017

published online

March 16, 2018 10.1055/s-0038-1625981. ISSN 0103-5355. than $1 \%$ of the cases. $^{3,4}$ Since the initial description by McCoyd, ${ }^{5}$ in 1974, of a VS presenting as a subarachnoid hemorrhage, up to 2013, more than 50 cases had been described in the literature. ${ }^{6}$ With the modern techniques of neuroimaging, this reported low frequency of hemorrhagic VS has been increasingly questioned. ${ }^{7}$ Its etiology remains unknown; however, some risk factors have been suggested, such as tumor size and tumor growth rate, the vascularity and histopathology of the tumor or even previous treatment with radiosurgery. ${ }^{3,6,8,9}$ The treatment of hemorrhagic vestibular
Copyright @ 2018 by Thieme Revinter Publicações Ltda, Rio de Janeiro, Brazil
License terms

(c) $(1) \$$ 

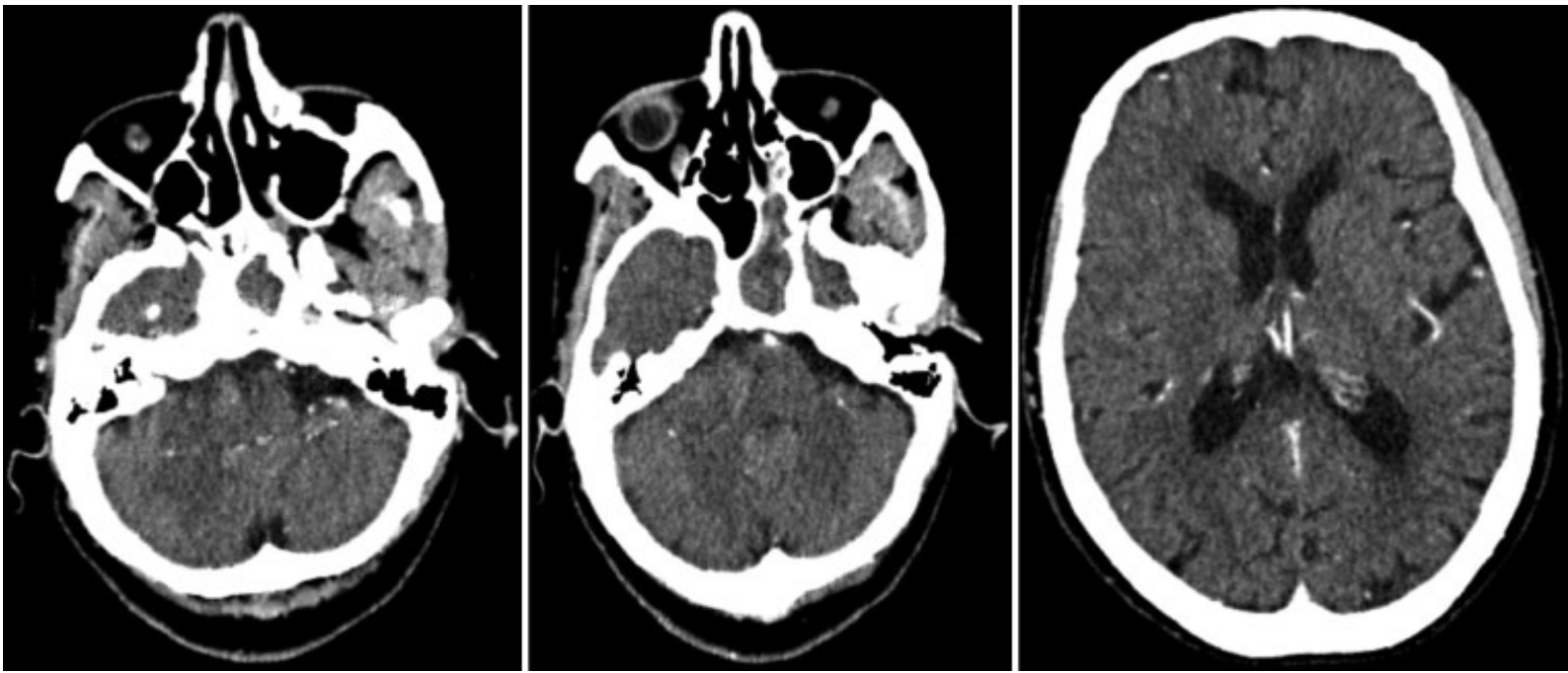

Fig. 1 Cerebellopontine angle lesion compatible with a vestibular schwannoma. Hannover class T4a. (December 2015).

schwannomas has, like the treatment of other VSs, three modalities: conservative treatment, surgery and radiosurgery. To our knowledge, our patient presents a rare case of hydrocephalus and peripheral facial paralysis secondary to hemorrhagic VS.

\section{Case Report Presentation}

We present the case of a 74-year-old woman with hypertension, dyslipidemia, congestive heart failure and an atrial fibrillation, and who had implanted a pacemaker several years ago. Among others, she took Varfarine (Teofarma, Pavia PV, Italy) because of the atrial fibrillation.

In December of 2015, the patient had a mild traumatic brain injury. She did a brain computed tomography (CT) scan, which revealed a CPA lesion that seemed to be a VS. After that, she reported to her primary care physician a longstanding right hypoacusia, which had not been treated previously. Because she could not do a brain MRI, a contrast enhanced CT scan of her brain was performed (-Fig. 1).
The lesion measured $3 \mathrm{~cm}$ in its longest diameter, extending into the internal acoustic meatus and reaching and compressing the brainstem (Hannover class T4a). The patient came to our clinic and, considering her pre-existing conditions and the fact that this finding was an 'incidentaloma', we proposed a conservative treatment. She remained asymptomatic until March of 2017, when she did the control brain CT scan we asked for (-Fig. 2).

As we can see in - Fig. 2, the CPA lesion remained with approximately the same volume and characteristics. However, a few days after the patient did the CT scan, she started to feel symptoms of confusion. When the patient came to our clinic, she was confused, with spatial and temporal disorientation, and had a peripheral facial palsy House-Brackmann (HB) grade IV-VI. She had no other symptoms. On the same day, the patient did another brain CT scan (-Fig. 3 ).

The brain CT scan revealed an intralesional hemorrhage inside the VS and a mild hydrocephalus. On the same day, we reversed the oral anticoagulation.
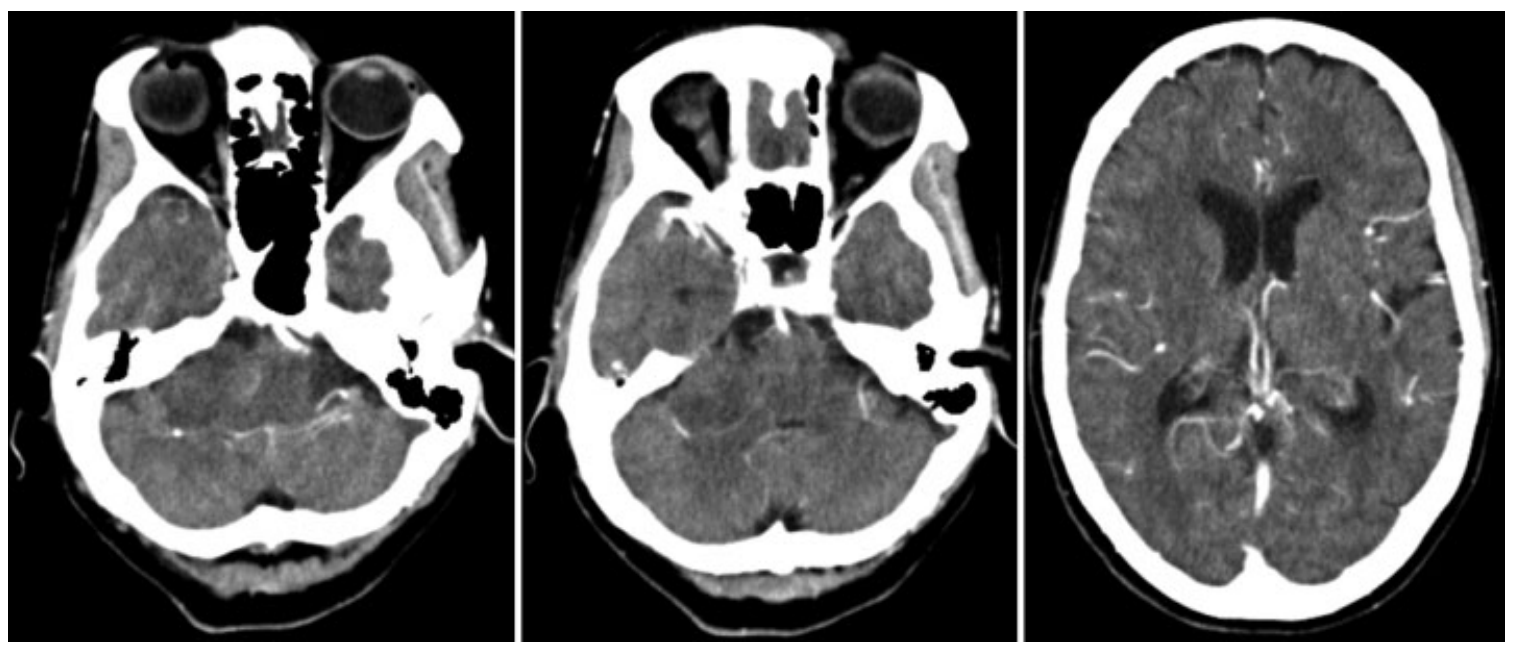

Fig. 2 Control brain computed tomography scan (March 2017). Tumor with approximately the same dimensions. 

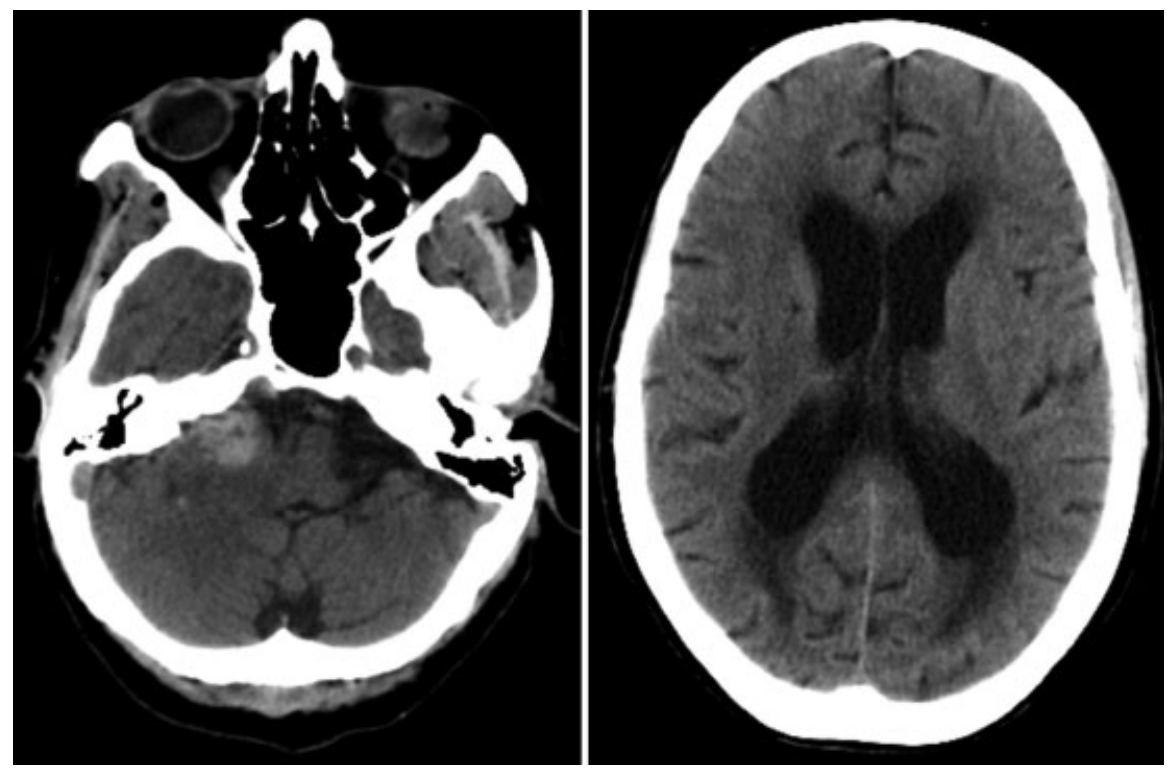

Fig. 3 Brain computed tomography scan after the new clinical picture (April 2017). Right image: intralesional hemorrhage; Left image: enlarged ventricles - hydrocephalus.

Concerning the new clinical picture, age and comorbidities, we decided to treat the patient with a ventriculoperitoneal shunt (VPS) - Codman Hakim programmable shunt set at 100 mm H2O (DePuy Synthes, West Chester, PA, USA). On the following day, we did another brain CT scan and thorax and abdominal X-rays to confirm the position of the VPS (-Fig. 4).

Two days after the surgery, the patient was discharged with no confusion and maintained the peripheral facial palsy HB grade IV-VI.

We saw the patient in our department one month after the surgery. She resumed her normal life and the peripheral facial palsy improved to a HB grade II-VI. She brought with her a control CT scan (-Fig. 5) performed at another hospital, which showed no hydrocephalus and revealed total reabsorption of the intralesional hemorrhage.

Considering the literature, we decided to propose no other treatment to the VS, and advised the patient not to return to the oral anticoagulation medication.

\section{Analysis and Discussion}

In this discussion, some questions should be raised regarding this case. The first of all is why did we decide not to treat a VS Hannover class T4a? According to Samy,${ }^{10}$ the surgical decision should include the following features: 1) large tumors (brainstem compression); 2) cystic tumors; 3) young patients ( $<50$ years); 4 ) vestibular-related main symptoms; 5) bilateral tumors in NF2 patients, and 6) patient's individual decision. Regarding radiosurgery, the standard indications include elderly patients, patients with high surgical risk, and patients with residual or recurrent tumors following microsurgical resection. ${ }^{11,12}$ We considered that this patient had no surgical conditions to undergo surgery at the time of the tumor presentation. Because the tumor presented as an 'incidentaloma', we considered that there was no evidence of tumor growth, so we decided, also, not to propose radiosurgery to the patient.
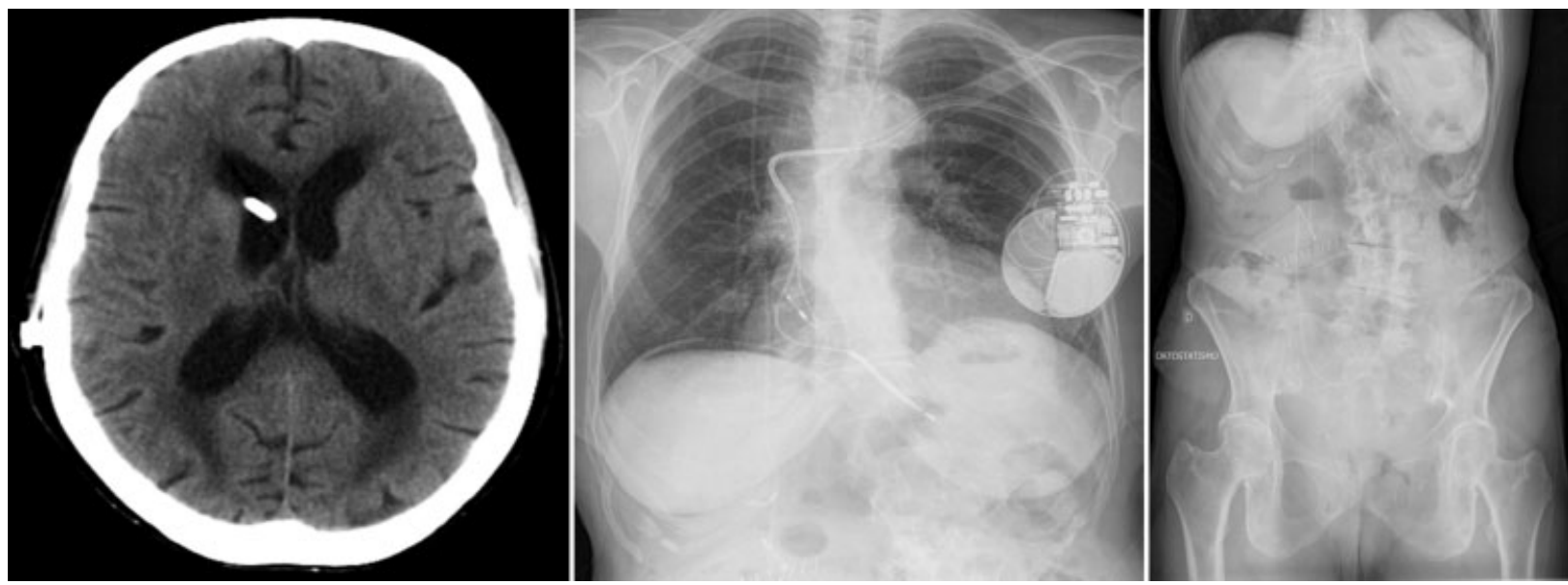

Fig. 4 Brain computed tomography scan, thorax and abdominal X-rays after the surgery. 

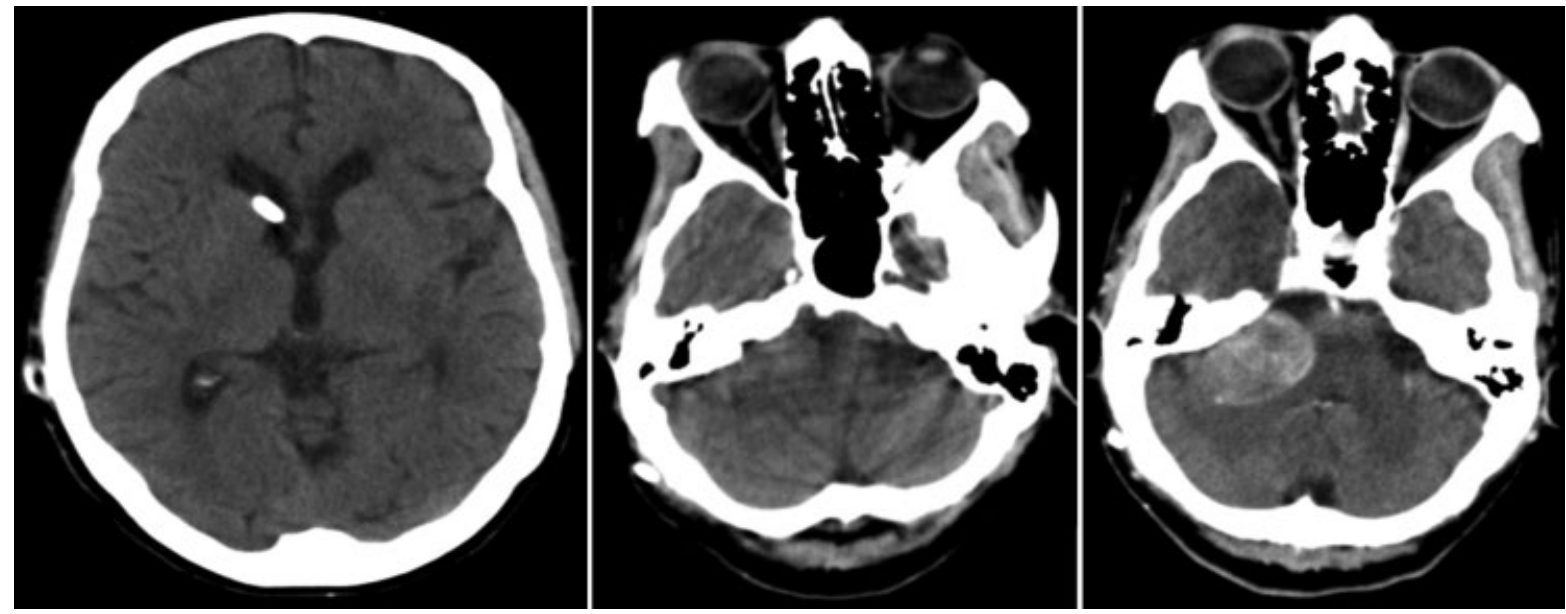

Fig. 5 Brain computed tomography scan one month after the surgery (May 2017).

After the hemorrhage and development of hydrocephalus and peripheral facial palsy, we were also faced with some decisions. How to treat the hydrocephalus and what was the expectation of solving the peripheral facial palsy concerning the various treatments we may offer? Since we interpreted the hydrocephalus as communicating (we assumed that there was a subarachnoid hemorrhage that precipitated the clinical syndrome), we realized that the only way to treat it was with a shunt diversion-so we did it. Since we did not expect the peripheral facial palsy to resolve with surgery or radiosurgery (it could actually get worse), we proposed no other kind of treatment at that stage- and it is actually almost completely resolved one month after the surgery.

The last question is: what to do next? We had evidence, before the hemorrhage, that the tumor was not growing, but it was bleeding. Since the clinical condition of the patient was the same, she remained not a suitable candidate for surgery. Besides that, we know from previous studies ${ }^{6}$ that radiosurgery is actually a risk factor for intralesional hemorrhage. With that in mind, we proposed that the patient did not undergo radiosurgery.

\section{Conclusion}

The vestibular schwannoma is the most common CPA lesion. The clinical presentation with hemorrhage corresponds to less than $1 \%$ of all tumors. Some recent works proposed that this may be as frequent as we thought in the natural history of this disease. In the treatment of hemorrhagic VS, the therapeutic armamentarium is the same as in other presentations. In this case, we think that neither surgery nor radiosurgery were good options to treat the hydrocephalus or the peripheral facial palsy-actually both might aggravate them. Thus, we treated the hydrocephalus with a VPS and hoped that the natural history of the disease favored the clinical condition of the patient, which indeed occurred.

Conflict of Interest

None.

\section{Acknowledgments}

We want to thank Margarida Calejo, MD, from Centro Hospitalar do Porto, for the help in the revision of the manuscript, particularly the English grammatical corrections.

\section{References}

1 Asari S, Katayama S, Itoh T, Tsuchida S, Furuta T, Ohmoto T. Neurinomas presenting as spontaneous intratumoral hemorrhage. Neurosurgery 1992;31(03):406-411, discussion 411-412

2 Paldor I, Chen AS, Kaye AH. Growth rate of vestibular schwannoma. J Clin Neurosci 2016;32:1-8

3 Benhaiem-Sigaux N, Ricolfi F, Torres-Díaz A, Keravel Y, Poirier J. Haemorrhagic acoustic neuroma with features of a vascular malformation. A case report. Neuroradiology 1999;41(10):795-798

4 Carlson ML, Driscoll CL, Link MJ, Inwards CY, Neff BA, Beatty CW. A hemorrhagic vestibular schwannoma presenting with rapid neurologic decline: a case report. Laryngoscope 2010;120(Suppl 4):S204

5 McCoyd K, Barron KD, Cassidy RJ. Acoustic neurinoma presenting as subarachnoid hemorrhage. Case report. J Neurosurg 1974;41 (03):391-393

6 Niknafs YS, Wang AC, Than KD, Etame AB, Thompson BG, Sullivan SE. Hemorrhagic vestibular schwannoma: review of the literature. World Neurosurg 2014;82(05):751-756

7 Sughrue ME, Kaur R, Kane AJ, et al. Intratumoral hemorrhage and fibrosis in vestibular schwannoma: a possible mechanism for hearing loss. J Neurosurg 2011;114(02):386-393

8 Dehdashti AR, Kiehl TR, Guha A. Vestibular Schwannomas presenting with haemorrhage: clinical presentation and histopathological evaluation of an unusual entity. $\mathrm{Br} \mathrm{J}$ Neurosurg 2009;23 (04):431-436

9 Kim SH, Youm JY, Song SH, Kim Y, Song KS. Vestibular schwannoma with repeated intratumoral hemorrhage. Clin Neurol Neurosurg 1998;100(01):68-74

10 Ramina R, Aguiar P, Tatagiba M. Vestibular schwannomas: current state of the art. In: M. Samii's Essentials in Neurosurgery. Springer-Verlag Berlin Heidelberg; 2008:175-184

11 Pollock BE, Lunsford LD, Flickinger JC, Clyde BL, Kondziolka D. Vestibular schwannoma management. Part I. Failed microsurgery and the role of delayed stereotactic radiosurgery. J Neurosurg 1998;89(06):944-948

12 Pollock BE, Lunsford LD, Kondziolka D, et al. Vestibular schwannoma management. Part II. Failed radiosurgery and the role of delayed microsurgery. J Neurosurg 1998;89(06):949-955 